\title{
Refined heart failure detection algorithm for improved clinical reliability of OptiVol alerts in CRT-D recipients
}

\author{
Mate Vamos ${ }^{1,2}$, Noemi Nyolczas ${ }^{2}$, Zsolt Bari², Peter Bogyi², Balazs Muk², \\ Barna Szabo ${ }^{2,3}$, Bettina Ancsin ${ }^{2,4}$, Robert G. Kiss ${ }^{2}$, Gabor Z. Duray ${ }^{2}$ \\ ${ }^{1}$ Department of Cardiology, University Hospital Frankfurt - Goethe University, \\ Frankfurt am Main, Germany \\ ${ }^{2}$ Department of Cardiology, Medical Centre - Hungarian Defence Forces, Budapest, Hungary \\ ${ }^{3}$ University Hospital Örebro, Örebro, Sweden \\ ${ }^{4}$ Eastbourne District General Hospital, Eastbourne, United Kingdom
}

\begin{abstract}
Background: The reliability of intrathoracic impedance monitoring for prediction of heart failure (HF) by implantable cardiac devices is controversial. Despite using additional device-based parameters described in the PARTNERS HF study, such as new onset of arrhythmias, abnormal autonomics, low biventricular pacing rate or patient activity level, the predictive power of device diagnostic algorithm is still in doubt. The objective of this study was to compare the device diagnostic algorithm described in the PARTNERS HF study to a newly developed algorithm applying refined diagnostic criteria.

Methods: Fourty two patients were prospectively enrolled who had been implanted with an intrathoracic impedance and remote monitoring capable implantable cardiac defibrillator with a cardiac resychronization therapy (CRT-D) device in this observational study. If a remote OptiVol ${ }^{T M}$ alert occurred, patients were checked for presence of HF symptoms. A new algorithm was derived from the original PARTNERS $H F$ criteria, considering more sensitive cut-offs and changes of patterns of the device-based parameters.

Results: During an average follow-up of 38 months, 722 remote transmissions were received. From the total of 128 transmissions with OptiVol alerts, 32 (25\%) corresponded to true HF events. Upon multivariate discriminant analysis, low patient activity, high nocturnal heart rate, and low CRT pacing $(<90 \%)$ proved to be independent predictors of true HF events (all $p<0.01$ ). Incorporating these three refined criteria in a new algorithm, the diagnostic yield of OptiVol was improved by increasing specificity from $37.5 \%$ to $86.5 \%$, positive predictive value from $34.1 \%$ to $69.8 \%$ and area under the curve from 0.787 to 0.922 ( $p<0.01)$, without a relevant loss in sensitivity (96.9\% vs. 93.8\%).

Conclusions: A refined device diagnostic algorithm based on the parameters of low activity level, high nocturnal heart rate, and suboptimal biventricular pacing might improve the clinical reliability of OptiVol alerts. (Cardiol J 2018; 25, 2: 236-244)
\end{abstract}

Key words: congestive heart failure, remote monitoring, intrathoracic impedance monitoring, CRT-D, OptiVol

Address for correspondence: Mate Vamos, MD, Department of Cardiology, Division of Clinical Electrophysiology, University Hospital Frankfurt - Goethe University, Theodor-Stern-Kai 7, D-60590 Frankfurt, Germany, tel: +49-69-6301-6666, fax: +49-69-6301-7017, e-mail: vamos.mate@gmail.com

Received: 04.02.2017

Accepted: 28.05.2017 


\section{Introduction}

Unfavourable prognostic impacts of recurrent hospitalizations in chronic systolic heart failure (HF) are well known [1]. Accordingly, several methods have been developed aiming at early detection of worsening HF with the potential for timely intervention to prevent hospitalizations and improve survival. Some of the cardiovascular implantable electronic devices offer extended monitoring capabilities of vital parameters which may help to predict HF events. Yu et al. [2] developed a detection algorithm called $\mathrm{OptiVol}^{\mathrm{TM}}$ to predict cardiac decompensation by applying Fluid Index derived from the changes of intrathoracic impedance, as a marker of lung fluid status. However, the reliability of OptiVol remained contradictory in further clinical trials $[3,4]$. In the prospective multicenter PARTNERS HF study (Program to Access and Review Trending Information and Evaluate Correlation to Symptoms in Patients with Heart Failure study), the clinical utility of impedance monitoring could have been improved by using a combined device diagnostic algorithm based on additional parameters such as: new onset of atrial fibrillation (AF), rapid ventricular rate during $\mathrm{AF}$, low patient activity levels, high night heart rate (HR), low heart rate variability (HRV), low percentage of biventricular pacing, and ventricular arrhythmias with implantable cardioverter-defibrillator (ICD) shocks $[5,6]$. In this trial the strongest predictor was the elevated Fluid Index (i.e. OptiVol ${ }^{\mathrm{TM}}$ alert). Although the applied device diagnostic algorithm could predict the following hospitalization with high probability, only in 213 of 1324 (16.1\%) high-risk periods proved to be associated with true HF events. In further studies the number of false positive or unexplained OptiVol alerts also remained remarkably high despite the combination with remote monitoring technics [7-10].

It was thus hypothesized that the reliability of OptiVol alerts could be improved with some modifications of the original PARTNERS HF criteria which considering more sensitive diagnostic values and changes of patterns in these parameters. In the present observational study, the aim was to compare the clinical applicability of device diagnostic algorithm described in PARTNERS HF study to a newly developed algorithm which applies refined diagnostic criteria.

\section{Methods}

\section{Study patients and study design}

All consecutive patients implanted with an OptiVol and wireless telemetry capable implant- able cardiac defibrillator with cardiac resychronization therapy (CRT-D) device (Medtronic Inc., Minneapolis, MN, US) in the Medical Center of Hungarian Defence Forces and signed to be followed up via the CareLink ${ }^{\circledast}$ remote monitoring system (Medtronic Inc., Minneapolis, MN, US) were prospectively recruited from April 2011 to June 2014. The optional function of intrathoracic impedance monitoring (OptiVol) was activated in all patients with an automatic remote alert, if the Fluid Index reaches $60 \Omega$-day.

Patients were followed up at our outpatient HF clinic every 3 months or if clinically indicated. Inoffice device control was performed semi-annualy by electrophysiologists. The transmitted CareLink data were evaluated by an electrophysiologist and $\mathrm{HF}$ specialist team weekly and within $24 \mathrm{~h}$ for clinically relevant alerts.

If an OptiVol alert occurred, all device monitored parameters were recorded and patients were interviewed by an independent $\mathrm{HF}$ specialist for the presence of HF symptoms via telephone calls and during additional outpatient visits, as necessary. An OptiVol alert was categorized as true positive (verified HF event) when signs and symptoms of decompensated HF required an increase in diuretic dose in an outpatient setting or hospitalization.

All patients signed an informed consent form. The study complies with the Declaration of Helsinki, and the study protocol was approved by the Institutional Ethics Committee.

\section{Assessment of original \\ PARTNERS HF criteria}

The original PARTNERS HF criteria were evaluated for all OptiVol alerts (Fluid Index $\geq 60 \Omega$-day) using a time-frame window of 20 days prior to an alert, and the sensitivity and specificity of the original PARTNERS HF device diagnostic algorithm were determined.

\section{New device diagnostic}

algorithm development

A refined diagnostic algorithm was derived from an OptiVol alert (Fluid Index $\geq 60 \Omega$-day) and the presence of further positive parameters in a 20 day time-frame window prior to the alert. The following modified diagnostic criteria were utilized: - new AF episode: $\geq 6 \mathrm{~h}$ on at least 1 day;

- high ventricular rate during AF: average ventricular rate during $\mathrm{AF} \geq 90 \mathrm{bpm}$ on at least $24 \mathrm{~h}$;

- lower patient activity level for at least 5 days:

- $\quad-2 \mathrm{~h} /$ day, if the prior average was $\geq 4 \mathrm{~h} /$ day,

- $-1 \mathrm{~h} /$ day, if the prior average was $<4 \mathrm{~h} /$ day, 
Table 1. Definition of the refined diagnostic criteria and differences to the original PARTNERS HF parameters.

\begin{tabular}{|c|c|c|}
\hline $\begin{array}{l}\text { Device measured } \\
\text { parameter }\end{array}$ & $\begin{array}{l}\text { Original PARTNERS HF } \\
\text { criteria }\end{array}$ & $\begin{array}{l}\text { Refined PARTNERS HF } \\
\text { criteria }\end{array}$ \\
\hline New AF episode & $\begin{array}{l}A F \geq 6 \text { h on at least } \\
1 \text { day without } \\
\text { persistent } A F\end{array}$ & $A F \geq 6 \mathrm{~h}$ on at least 1 day without persistent $A F$ \\
\hline Ventricular rate during $\mathrm{AF}$ & $\begin{array}{l}\mathrm{AF} \geq 24 \mathrm{~h} \text { and daily } \\
\text { average ventricular rate } \\
\text { during } \mathrm{AF} \geq 90 \mathrm{bpm} \text {, on } \\
\text { at least } 24 \mathrm{~h}\end{array}$ & $\begin{array}{l}A F \geq 24 \mathrm{~h} \text { and daily average ventricular rate during } \\
A F \geq 90 \mathrm{bpm}, \text { on at least } 24 \mathrm{~h}\end{array}$ \\
\hline Patient activity level & $\begin{array}{l}\text { Average activity } \\
<1 \text { h over } 7 \text { days }\end{array}$ & $\begin{array}{l}\text { Lower average activity over } 5 \text { days with } \\
\text { - }-2 \mathrm{~h} / \text { day, if the prior average was } \geq 4 \mathrm{~h} / \text { day } \\
\text { - }-1 \mathrm{~h} / \mathrm{day} \text {, if the prior average was }<4 \mathrm{~h} / \text { day } \\
\text { - except, if prior average was permanently }<1 \mathrm{~h} / \text { day } \\
\text { or activity decline for extracardiac reason (e.g. elective } \\
\text { surgery, any musculoskeletal disorders etc.) }\end{array}$ \\
\hline Nocturnal heart rate & $\begin{array}{l}\text { Average night heart rate } \\
>85 \mathrm{bpm} \text { for } \\
7 \text { consecutive days }\end{array}$ & $\begin{array}{l}\text { Average night heart rate }>85 \mathrm{bpm} \text { or elevated } \\
\text { with } \geq 20 \mathrm{bpm} \text { to the prior average for at least } \\
5 \text { consecutive days }\end{array}$ \\
\hline Heart rate variability & $\begin{array}{l}<60 \text { ms every day } \\
\text { for } 1 \text { week }\end{array}$ & $\begin{array}{l}<60 \mathrm{~ms} \text { every day for } 1 \text { week, except if permanently } \\
\text { under } 60 \mathrm{~ms}\end{array}$ \\
\hline Biventricular pacing rate & $<90 \%$ for 5 of 7 days & $<90 \%$ for 5 of 7 days, except if permanently $<90 \%$ \\
\hline Ventricular arrhythmias & $\begin{array}{l}\geq 1 \text { shocks during the } \\
\text { evaluation period }\end{array}$ & $\geq 1$ shocks or ATPs during the evaluation period \\
\hline
\end{tabular}

AF - atrial fibrillation; ATP - anti-tachycardia pacing; PARTNERS HF — Program to Access and Review Trending Information and Evaluate Correlation to Symptoms in Patients with Heart Failure study

- $\quad$ except (parameter was defined negative), if prior average was permanently under $1 \mathrm{~h} /$ day or activity decline was related to extracardiac reason (e.g. elective surgery, musculoskeletal disorders etc.);

- elevated nocturnal HR: average night HR $>85 \mathrm{bpm}$ or elevated with $\geq 20 \mathrm{bpm}$ to the prior average for at least 5 consecutive days;

- low HRV: < 60 ms every day for 1 week, except (parameter was defined negative), if permanently under $60 \mathrm{~ms}$;

- low biventricular pacing rate: $<90 \%$ for at least $5-7$ days, except (parameter was defined negative), if permanently $<90 \%$;

- ventricular arrhythmias: treated by 1 or more ICD shocks or successful anti-tachycardia pacing.

The differences between the original PARTNERS HF criteria and these refined parameters are highlighted in Table 1. The utilized modifications are mainly derived from clinical experience with the device based diagnostic.

\section{Statistical analysis}

Statistical analyses were performed using STATISTICA version 10.0 (Tulsa, Oklahoma, USA), SAS version 9.4 (SAS Institute Inc., Cary, NC, USA) and MedCalc version 14.12.0 (Ostend, Belgium) software. Numerical values are presented as mean \pm standard deviation. Multivariate discriminant analysis was used to assess the association between device based parameters and the progression of HF. Parameters independently associated with true HF events $(\mathrm{p}<0.05)$ were included in the final risk score. The predictive power of the original and refined clinical algorithms was described with sensitivity, specificity, positive and negative predictive statistics and the receiver operating characteristic method (ROC analysis). To obtain an unbiased ROC analysis (training and validation was performed on the same population) cross-validation was performed. The crossvalidation of ROC curves and confidence interval calculations were performed with SAS software by the "Proc Logistic" procedure. 
Table 2. Baseline characteristics.

\begin{tabular}{|c|c|}
\hline Total & 42 \\
\hline \multicolumn{2}{|l|}{ Demographics: } \\
\hline Age [years] & $64.0 \pm 11.7$ \\
\hline Gender (male) & $81.0 \%$ \\
\hline \multicolumn{2}{|l|}{ Heart failure etiology: } \\
\hline Ischemic & $57.1 \%$ \\
\hline Non-ischemic: & $42.9 \%$ \\
\hline Valvular & $4.8 \%$ \\
\hline Non-compaction cardiomyopathy & $2.4 \%$ \\
\hline Toxic & $2.4 \%$ \\
\hline Myocarditis & $9.5 \%$ \\
\hline DCM/Genetic/Unknown & $23.8 \%$ \\
\hline \multicolumn{2}{|l|}{ Indication for defibrillator implantation: } \\
\hline Primary prevention & $78.6 \%$ \\
\hline Secondary prevention & $21.4 \%$ \\
\hline \multicolumn{2}{|l|}{ Characteristics: } \\
\hline LVEF [\%] & $26.9 \pm 6.1$ \\
\hline NYHA class & $2.42 \pm 0.78$ \\
\hline LBBB [\%] & 76.2 \\
\hline QRS duration [ms] & $151 \pm 24$ \\
\hline \multicolumn{2}{|l|}{ Comorbidities: } \\
\hline Atrial fibrillation paroxysmal & $40.5 \%$ \\
\hline Atrial fibrillation permanent & $23.8 \%$ \\
\hline Diabetes mellitus & $38.1 \%$ \\
\hline Hypertension & $85.7 \%$ \\
\hline Hyperlipidaemia & $26.2 \%$ \\
\hline Chronic pulmonary disease & $16.7 \%$ \\
\hline History of CKD* & $59.5 \%$ \\
\hline \multicolumn{2}{|l|}{ Laboratory values at baseline: } \\
\hline Creatinine $[\mu \mathrm{mol} / \mathrm{L}]$ & $124.8 \pm 52.7$ \\
\hline Hemoglobin [g/L] & $128.8 \pm 17.0$ \\
\hline \multicolumn{2}{|l|}{ Cardiovascular medication: } \\
\hline Beta-blockers & $100.0 \%$ \\
\hline ACEI/ARB & $92.9 \%$ \\
\hline Diuretics & $83.3 \%$ \\
\hline MRA & $78.6 \%$ \\
\hline Nitrates and dihydralazine & $81.0 \%$ \\
\hline Antiplatelet therapy & $59.5 \%$ \\
\hline Oral anticoagulants & $64.3 \%$ \\
\hline Statins & $76.2 \%$ \\
\hline Amiodarone & $19.0 \%$ \\
\hline Digoxin & $11.9 \%$ \\
\hline
\end{tabular}

${ }^{*} \mathrm{GFR}<60 \mathrm{~mL} / \mathrm{min}$; ACEI — angiotensin converting enzyme inhibitor; ARB - angiotensin II receptor antagonists; CKD — chronic kidney diesease; DCM - dilated cardiomyopathy; LBBB — left bundle branch block; LVEF — left ventricular ejection fraction; MRA - mineralocorticoid receptor antagonists; NYHA - New York Heart Association functional classification

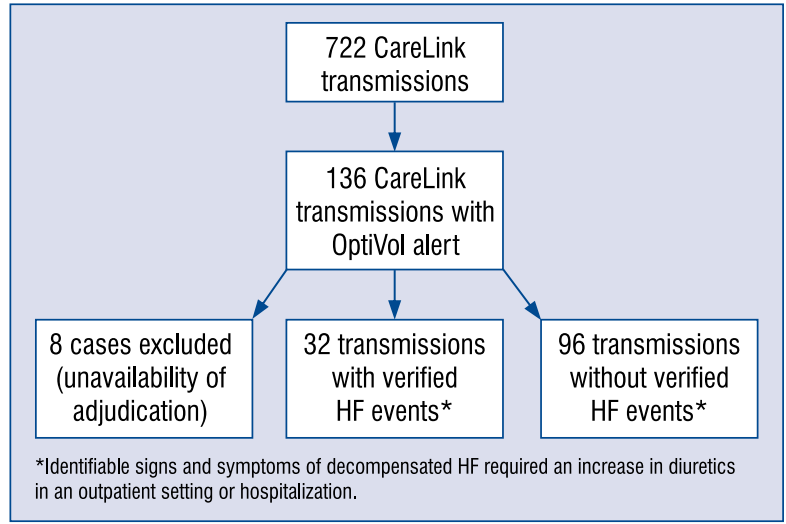

Figure 1. Flowchart of CareLink transmissions during the study period; HF — heart failure.

\section{Results}

\section{Patient cohort and clinical characteristics}

The average follow-up of the 42 enrolled patients was $38.0 \pm 23.6$ months. Detailed patient baseline data are summarized in Table 2 . It should be highlighted that all patients $(100 \%)$ were on beta-receptor blockers and $45.2 \%$ of them received the maximum recommended dose.

Five patients died, 2 underwent heart transplantation, 1 required an assist device implantation and in 1 case the CRT-D system had to be explanted due to infection.

\section{OptiVol alerts and heart failure events}

Altogether 722 remote transmissions were received during the follow-up period. After the exclusion of 8 transmissions due to the unavailability of HF specialist adjudication 128 transmissions with OptiVol alerts (Fluid Index $\geq 60$ $\Omega$-day) were included in this analysis. Verified HF events were observed in $32(25 \%)$ cases (Fig. 1) with need for hospitalization in 8 cases. For the remaining cases no clinical events were identified or clear extracardiac causes were found in the background of OptiVol alerts (typically infection of the upper/lower respiratory tract, acute exacerbation of chronic obstructive pulmonary disease, surgery for any reason).

\section{Assessment of the original PARTNERS HF criteria in our patient population}

The classic PARTNERS HF diagnostic algorithm was positive in 31 of 32 cases with true deterioration of $\mathrm{HF}$ (sensitivity $96.9 \%, 95 \%$ confidence interval [CI] 83.8-99.9; negative predictive value [NPV] 97.3\%, 95\% CI 85.8-99.9), however, the 
Table 3. Prognostic characteristics of the original and the refined diagnostic criteria.

\begin{tabular}{lcc}
\hline & $\begin{array}{c}\text { PARTNERS HF classic } \\
\text { (without OptiVol } \geq 100)\end{array}$ & $\begin{array}{c}\text { OptiVol + } 1 \\
\text { modified criteria }\end{array}$ \\
\hline Sensitivity $(95 \% \mathrm{Cl})$ & $96.9 \%(83.8-99.9)$ & $93.8 \%(79.2-99.2)$ \\
Specificity $(95 \% \mathrm{Cl})$ & $37.5 \%(27.8-48.0)$ & $86.5 \%(78.0-92.6)$ \\
Positive predictive value $(95 \% \mathrm{Cl})$ & $34.1 \%(24.5-44.7)$ & $69.8 \%(53.9-82.8)$ \\
Negative predictive value $(95 \% \mathrm{Cl})$ & $97.3 \%(85.8-99.9)$ & $97.6 \%(91.8-99.7)$ \\
ROC-analysis/AUC $(95 \% \mathrm{Cl}) *$ & $0.787(0.704-0.869)$ & $0.922(0.869-0.974)$ \\
AUC with validation $(95 \% \mathrm{Cl}) \dagger$ & $0.679(0.568-0.790)$ & $0.858(0.767-0.948)$ \\
\hline
\end{tabular}

*p between the two algorithms $<0.01 ;$ p between the two algorithms $<0.01$

AUC - area under the curve; $\mathrm{Cl}$ - confidence interval; PARTNERS HF — Program to Access and Review Trending Information and

Evaluate Correlation to Symptoms in Patients with Heart Failure study; ROC-analysis - receiver operating characteristic method

Table 4. Results of the multivariate discriminant analysis.

\begin{tabular}{lccc}
\hline Device measured parameters & Wilks' lambda & Partial lambda & P \\
\hline New AF episode & 0.421 & 0.986 & 0.19 \\
Elevated HR during AF & 0.422 & 0.996 & 0.47 \\
Patient activity & 0.663 & 0.638 & $<0.001$ \\
Elevated nocturnal HR & 0.485 & 0.871 & $<0.001$ \\
Decreased HR variability & 0.428 & 0.989 & 0.23 \\
Biventricular pacing < 90\% & 0.532 & 0.795 & $<0.001$ \\
ICD therapy (ATP/shock) & 0.424 & 0.9784 & 0.1 \\
\hline
\end{tabular}

AF — atrial fibrillation; ATP — anti-tachycardia pacing; HR — heart rate; ICD — implantable cardioverter defibrillator

specificity remained very low with 60 false positive events (specificity $37.5 \%$, 95\% CI $27.8-48.0 \%$; positive predictive value [PPV] $34.1 \%, 95 \% \mathrm{CI}$ 24.5-44.7) (Table 3).

\section{Assessment of the new device} diagnostic algorithm

In multivariate discriminant analysis of the refined diagnostic criteria, lower activity levels, increased nocturnal HR, and suboptimal biventricular pacing proved to be independent predictors for cardiac decompensation (Table 4).

Applying our refined algorithm which includes OptiVol alert events (Fluid Index $\geq 60 \Omega$-day) and the presence of at least one of the aforementioned modified diagnostic criteria the number of false positive alerts decreased from 60 to 13 (specificity $86.5 \%$, 95\% CI $78.0-92.6 \%$; PPV $69.8 \%, 95 \%$ CI 53.9-82.8\%) without compromising the sensitivity (sensitivity $93.8 \%$, 95\% CI $79.2-99.2 \%$; NPV 97.6\%, 95\% CI 91.8-99.7\%) (Table 3). The diagnostic yield of the modified OptiVol algorithm

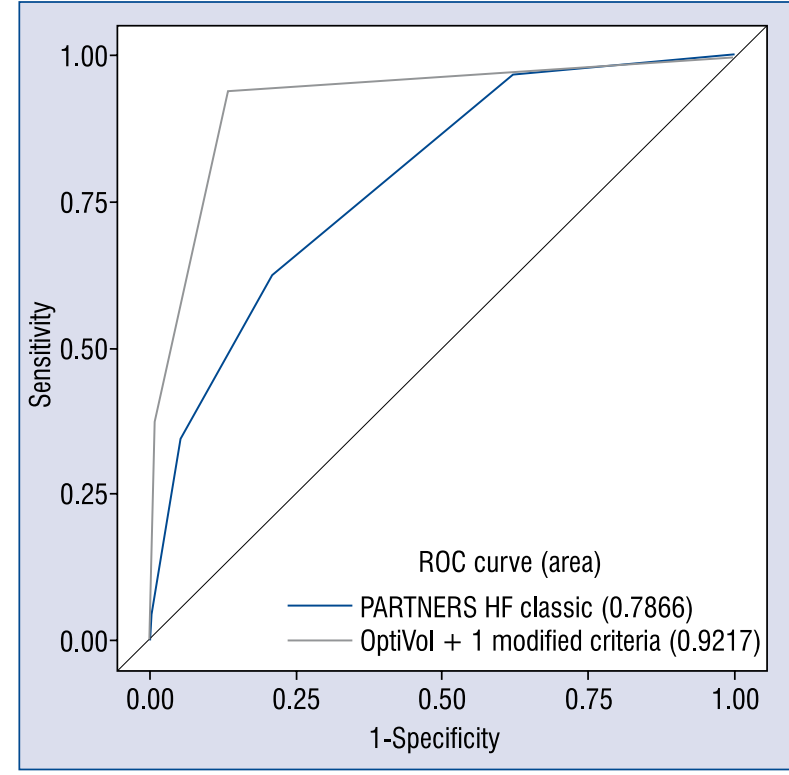

Figure 2. Comparison of receiver operating characteristic (ROC) curves: classic PARTNERS HF vs. modified diagnostic algorithm. 
assessed with ROC-analysis was also improved when compared to the classic PARTNERS HF diagnostic algorithm (AUC 0.787, 95\% CI 0.704-0.869 vs. AUC $0.922,95 \%$ CI $0.869-0.974, \mathrm{p}<0.01$ ) (Table 3, Fig. 2).

On cross-validation of the ROC-curves the difference between the two algorithms remained significant (AUC $0.679,95 \%$ CI $0.568-0.790$ vs. AUC $0.858,95 \%$ CI $0.767-0.948, \mathrm{p}<0.01$ ) (Table 3 ).

\section{Discussion}

\section{Main results}

In this prospective, long-term follow-up study of optimally treated HF patients with remote monitoring capable CRT-D devices, the diagnostic yield of OptiVol alerts could be improved using a newly developed diagnostic algorithm based on the original PARTNERS HF criteria.

In this new diagnostic algorithm, the modification of the original PARTNERS HF criteria included the refinement of cut-off values and the exclusion of cases with permanent positivity of the assessed parameters. Lower activity levels, increased nocturnal HR, and suboptimal biventricular pacing proved to be predictors for HF events.

\section{Prognostic parameters}

Patient activity measured by cardiac implantable electronic devices were evaluated alone [11-13] or together with other diagnostics [5, 6] in previous studies. Conraads et al. [11] demonstrated that higher levels of physical activity early after defibrillator implantation was associated with better outcomes in terms of mortality and HF hospitalization. In a single-center study of $164 \mathrm{CRT}$ recipients both 6 -min walk test and device-based measures of higher physical activity predicted reverse remodeling and HF hospitalizations [12]. In a recent, large-volume observational study derived from the ALTITUDE registry, device-detected activity strongly correlated with survival [13]. Several comorbidities and clinical factors (such as chronic obstructive lung disease, elective surgery, musculoskeletal disorders, etc.) were not taken into account in these analyses, however, these conditions could strongly influence the physical activity. This study tried to eliminate these confounding factors with the modification of the original criterion to exclude cases, where the prior average was $<1 \mathrm{~h} /$ /day permanently or activity decline was related to an extra cardiac reason.

Elevated HR is thought to be a marker of pathological autonomic response and correlates with worse prognoses in HF [14]. Post-hoc-analyses of BEAUTIFUL and SHIFT studies have confirmed the prognostic importance of HR $[15,16]$. In the observational study of Adamson et al. [17], nighttime HR was higher in CRT recipients who were hospitalized or died, compared with those with only minor exacerbations or those without any HF events.

According to the current guidelines CRT pacing rate should be as close to $100 \%$ as possible. The clinical benefit is strongly associated with a higher percentage of biventricular pacing as demonstrated in several reports [18]. Decrease in CRT pacing ( $<80 \%$ over $48 \mathrm{~h}$ ) was also one of the most frequent findings in the telemetry data, leading to additional follow-up visits in the IN-TIME study [19]. This randomised, controlled, multi-center study could demonstrate that remote monitoring (thoracic impedance measurements were not included) could improve mortality over standard care.

\section{Non-prognostic parameters}

The overall low specificity of the original PARTNERS HF algorithm may reflect the low clinical relevance of some parameters that were used. Consistently positive parameters such as long-term low patient activity level, long-standing low HRV, or persistently low percentage of biventricular pacing prior to an event do not play a role in prediction. These parameters represent the clinical status of the patient, but do not have enough predictive power to identify clinical events occurring in the subsequent few weeks. Therefore, the change but not the absolute value of these parameters may have significantly greater clinical relevance during the index period.

Although several clinical data suggest that HRV can have an inverse correlation with the progression of $\mathrm{HF}$ [17] and could improve with CRT [20], we strongly believe that this parameter (HRV in patients treated with CRT) is responsible for several false positive cases when applying the classic PARTNERS HF criteria. In patients on beta-blockers with a maximum tolerated dose, a high percentage of atrial pacing is frequently present, making the HRV calculation useless or misleading. Even in cases of permanent AF, the value of HRV should be expected permanently under $60 \mathrm{~ms}$, but it does not necessarily mean an unstable clinical condition. Figure 3 illustrates a case with an increase in HRV, while the patient status worsened because of an increase in heart rate and loss of CRT stimulation. 


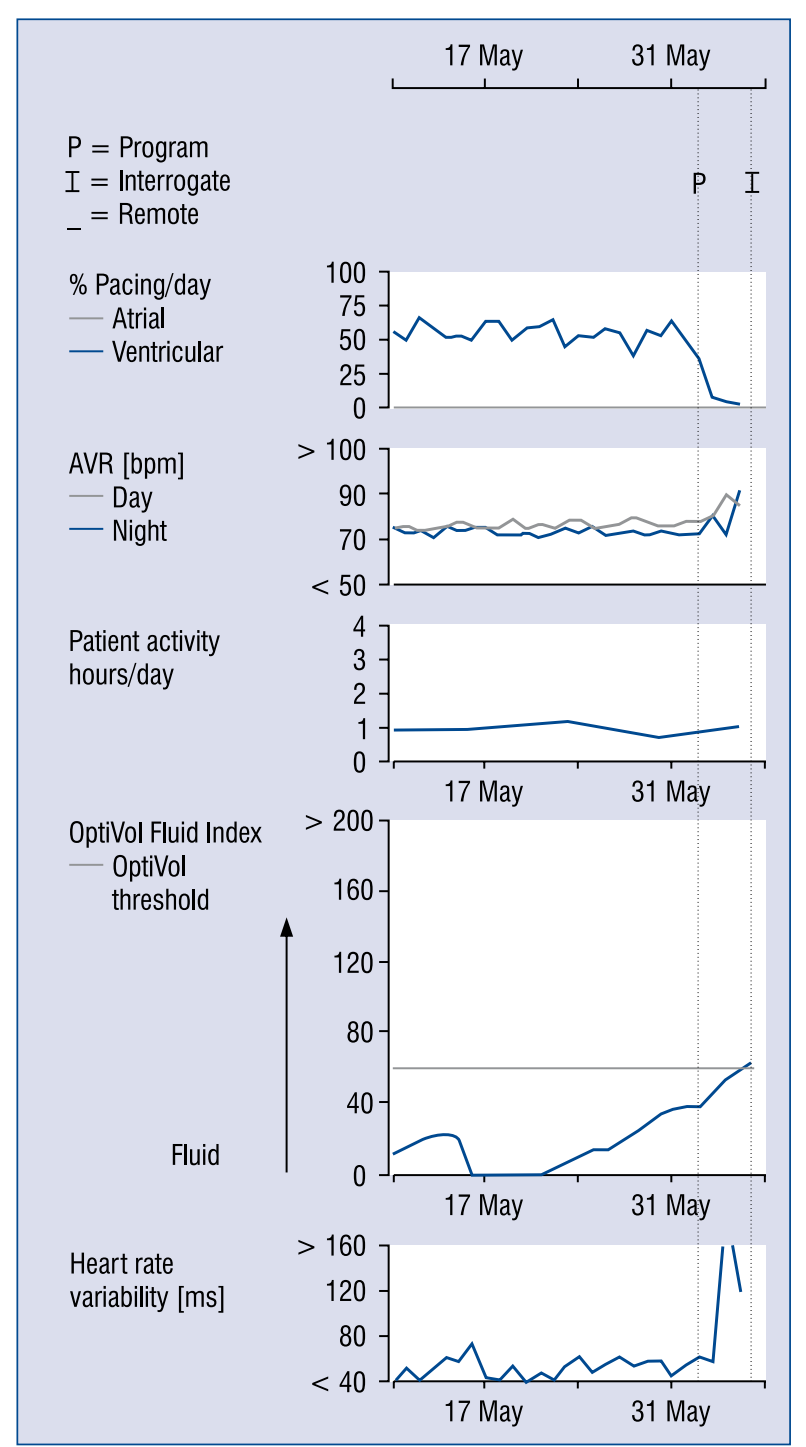

Figure 3. Changes of device detected parameters in a patient with decompensated heart failure (heart rate variablity increases, while the patient status was worsened because of an increase in average ventricular rate and loss of biventricular stimulation); AVR - average ventricular rate.

Acute exacerbations of congestive HF are believed to trigger ventricular arrhythmias through multiple potential mechanisms. The phenomenon described as mechano-electrical feedback causes an acute increase in filling pressure, which can lead to electrical instability [21,22]. A temporal association between malignant ventricular arrhythmias and volume overload detected by OptiVol was already demonstrated in two observational studies [23, 24]. The most likely reason for statistical non-significance of this parameter was the rare occurrence of malignant arrhythmias in the present patient cohort.
Predictive value of combined diagnostic algorithm in previous studies

Since the publication of PARTNERS HF trial several attempts have been made to develop a more reliable risk assessment model based on combined device based data. In the EVOLVO study some of the original PARTNERS HF criteria were used for remote monitoring of ICD patients, and a reduction in the rate of emergency admissions and urgent inoffice visits was demonstrated in the remote arm [25]. Gula et al. [26] acknowledging the limitations of the original PARTNERS HF criteria, worked out a novel diagnostic algorithm and validated it with convincing results in a post-hoc analysis of the RAFT trial. In phase 1 of MORE-CARE randomized study delay from the device-detected events to clinical decision was shorter and fewer in-hospital visits were required in the remote monitored group, however, the annual rate of all-cause hospitalizations could not be reduced [27]. Nonetheless, in two recently published, randomized trials of OptiVol combined with remote monitoring no significant influence on HF-related hospitalizations, ICD shocks, or mortality was found [9, 28]. Also the second phase of the MORE-CARE study could not demonstrate that decision making guided by such remote-monitoring protocol exerts a positive impact on hard endpoints [27].

\section{Limitations of the study}

This single-center observational study is subject to all potential limitations of this kind of analysis. First of all, the limited number of included patients should be highlighted. However, the average follow-up period (38 months) was longer with a high number of OptiVol alerts than in most of the previous reports. Furthermore, the presented findings can only help to exclude false positive cases from the current OptiVol alerts, as the study design was not aimed to identify HF episodes undetectable by the OptiVol algorithm. This study protocol consisted of at least 1 patient contact after an OptiVol alert. Since OptiVol alerts may occur 7-14 days before clinical symptoms of HF develop, repeated patient contact after the initial OptiVol alert could have possibly revealed some additional HF events. One important difference to the original PARTNERS HF study design should be also highlighted: Fluid Index $\geq 100 \Omega$-day has not been assigned in our analysis. Although the main idea of such a monitoring tool is to early identify risk patients as they reached an alert level, a scoring system using higher fluid index values might signal an alarm too late. It should be also noted that 
recently a new OptiVol algorithm (OptiVol 2.0) was developed by the manufacturer for the calculation of the Fluid Index and the Reference Impedance [29]. In the presented patient population one part of the investigation used devices still working with OptiVol 1.0 (Concerto CRT-D, Concerto II CRT-D, Consulta CRT-D) the other part used the new algorithm (Viva Quad XT CRT-D, Protecta XT CRT-D, Brava Quad CRT-D).

\section{Conclusions}

A refined device diagnostic algorithm based on parameters of low activity level, high nocturnal $\mathrm{HR}$, and suboptimal biventricular pacing could improve clinical reliability of OptiVol alerts in the presented patient cohort. These results are hypothesis generating, and hence this strategy of risk assessment should be prospectively tested in larger patient cohorts.

\section{Acknowledgements}

The authors would like to thank especially Prof. Stefan H. Hohnloser for his valuable suggestions and to Dr. Andras Paksy and to Prof. Dr. Elek Dinya for their advice in the statistical segment of the study. The contribution of Dr. Leticia Papp, Dr. Balazs Polgar, Dr. Aron Sztaniszlav, and Dr. Katarina Vargova in Device/CareLink-follow-up, the contribution of Dr. Tunde Borsanyi, and Dr. Miklos Dekany in HF follow-up, and the technical expertise of Zoltan Melicher and Laszlo Neder from Medtronic Hungary are also greatly appreciated.

Conflict of interest: None declared

\section{References}

1. Setoguchi S, Stevenson LW, Schneeweiss S. Repeated hospitalizations predict mortality in the community population with heart failure. Am Heart J. 2007; 154(2): 260-266, doi: 10.1016/j. ahj.2007.01.041, indexed in Pubmed: 17643574.

2. Yu CM, Wang Li, Chau E, et al. Intrathoracic impedance monitoring in patients with heart failure: correlation with fluid status and feasibility of early warning preceding hospitalization. Circulation. 2005; 112(6): 841-848, doi: 10.1161/CIRCULATIONAHA.104.492207, indexed in Pubmed: 16061743.

3. van Veldhuisen DJ, Braunschweig F, Conraads V, et al. DOTHF Investigators. Intrathoracic impedance monitoring, audible patient alerts, and outcome in patients with heart failure. Circulation. 2011; 124(16): 1719-1726, doi: 10.1161/CIRCULATIONAHA.111.043042, indexed in Pubmed: 21931078.

4. Conraads VM, Tavazzi L, Santini M, et al. Sensitivity and positive predictive value of implantable intrathoracic impedance monitoring as a predictor of heart failure hospitalizations: the SENSEHF trial. Eur Heart J. 2011; 32(18): 2266-2273, doi: 10.1093/ eurheartj/ehr050, indexed in Pubmed: 21362703.
5. Whellan DJ, Ousdigian KT, Al-Khatib SM, et al. Combined heart failure device diagnostics identify patients at higher risk of subsequent heart failure hospitalizations: results from PARTNERS HF (Program to Access and Review Trending Information and Evaluate Correlation to Symptoms in Patients With Heart Failure) study. J Am Coll Cardiol. 2010; 55(17): 1803-1810, doi: 10.1016/j.jacc.2009.11.089, indexed in Pubmed: 20413029.

6. Sharma V, Rathman LD, Small RS, et al. Stratifying patients at the risk of heart failure hospitalization using existing device diagnostic thresholds. Heart Lung. 2015; 44(2): 129-136, doi: 10.1016/j.hrtlng.2014.07.007, indexed in Pubmed: 25543319.

7. Yang XW, Hua W, Ding LG, et al. OptiVol fluid index predicts acute decompensation of heart failure with a high rate of unexplained events. J Geriatr Cardiol. 2013; 10(3): 253-257, doi: 10.3969/j. issn.1671-5411.2013.03.012, indexed in Pubmed: 24133513.

8. Aizawa Y, Takatsuki S, Kashimura S, et al. Thoracic impedance as a therapeutic marker of acute decompensated heart failure. Int J Cardiol. 2014; 174(3): 840-842, doi: 10.1016/j.ijcard.2014.04.159, indexed in Pubmed: 24801075.

9. Lüthje L, Vollmann D, Seegers J, et al. A randomized study of remote monitoring and fluid monitoring for the management of patients with implanted cardiac arrhythmia devices. Europace. 2015; 17(8): 1276-1281, doi: 10.1093/europace/euv039, indexed in Pubmed: 25983310.

10. Nishii N, Kubo M, Okamoto Y, et al. Decreased Intrathoracic Impedance Associated With OptiVol Alert Can Diagnose Increased B-Type Natriuretic Peptide - MOMOTARO (Monitoring and Management of OptiVol Alert to Reduce Heart Failure Hospitalization) Study. Circ J. 2015; 79(6): 1315-1322, doi: 10.1253/ circj.CJ-15-0076, indexed in Pubmed: 25787230.

11. Conraads VM, Spruit MA, Braunschweig F, et al. Physical activity measured with implanted devices predicts patient outcome in chronic heart failure. Circ Heart Fail. 2014; 7(2): 279-287, doi: 10.1161/CIRCHEARTFAILURE.113.000883, indexed in Pubmed: 24519908.

12. Vegh EM, Kandala J, Orencole M, et al. Device-measured physical activity versus six-minute walk test as a predictor of reverse remodeling and outcome after cardiac resynchronization therapy for heart failure. Am J Cardiol. 2014; 113(9): 1523-1528, doi: 10.1016/j.amjcard.2014.01.430, indexed in Pubmed: 24641966 .

13. Kramer DB, Mitchell SL, Monteiro J, et al. Patient Activity and Survival Following Implantable Cardioverter-Defibrillator Implantation: The ALTITUDE Activity Study. J Am Heart Assoc. 2015; 4(5), doi: 10.1161/JAHA.115.001775, indexed in Pubmed: 25979902.

14. McAlister FA, Wiebe N, Ezekowitz JA, et al. Meta-analysis: betablocker dose, heart rate reduction, and death in patients with heart failure. Ann Intern Med. 2009; 150(11): 784-794, indexed in Pubmed: 19487713.

15. Fox K, Ford I, Steg PhG, et al. Relationship between ivabradine treatment and cardiovascular outcomes in patients with stable coronary artery disease and left ventricular systolic dysfunction with limiting angina: a subgroup analysis of the randomized, controlled BEAUTIFUL trial. Eur Heart J. 2009; 30(19): 2337-2345, doi: 10.1093/eurheartj/ehp358, indexed in Pubmed: 19720635.

16. Böhm M, Swedberg K, Komajda M, et al. Heart rate as a risk factor in chronic heart failure (SHIFT): the association between heart rate and outcomes in a randomised placebo-controlled trial. Lancet. 2010; 376(9744): 886-894, doi: 10.1016/S01406736(10)61259-7, indexed in Pubmed: 20801495. 
17. Adamson PB, Smith AL, Abraham WT, et al. Continuous autonomic assessment in patients with symptomatic heart failure: prognostic value of heart rate variability measured by an implanted cardiac resynchronization device. Circulation. 2004; 110(16): 2389-2394, doi: 10.1161/01.CIR.0000139841.42454.78, indexed in Pubmed: 15313946.

18. Brignole M, Auricchio A, Baron-Esquivias G, et al. 2013 ESC Guidelines on cardiac pacing and cardiac resynchronization therapy: the Task Force on cardiac pacing and resynchronization therapy of the European Society of Cardiology (ESC). Developed in collaboration with the European Heart Rhythm Association (EHRA). Eur Heart J. 2013; 34(29): 2281-2329, doi: 10.1093/ eurhearti/eht150, indexed in Pubmed: 23801822.

19. Hindricks G, Taborsky M, Glikson M, et al. Implant-based multiparameter telemonitoring of patients with heart failure (IN-TIME): a randomised controlled trial. Lancet. 2014; 384(9943): 583-590, doi: 10.1016/S0140-6736(14)61176-4, indexed in Pubmed: 25131977.

20. Fantoni C, Raffa S, Regoli F, et al. Cardiac resynchronization therapy improves heart rate profile and heart rate variability of patients with moderate to severe heart failure. J Am Coll Cardiol. 2005; 46(10): 1875-1882, doi: 10.1016/j.jacc.2005.06.081, indexed in Pubmed: 16286175.

21. Sarubbi B, Ducceschi V, Santangelo L, et al. Arrhythmias in patients with mechanical ventricular dysfunction and myocardial stretch: role of mechano-electric feedback. Can J Cardiol. 1998; 14(2): 245-252, indexed in Pubmed: 9520861.

22. Narayan SM, Drinan DD, Lackey RP, et al. Acute volume overload elevates T-wave alternans magnitude. J Appl Physiol. 2007; 102(4): 1462-1468, doi: 10.1152/japplphysiol.00965.2006, indexed in Pubmed: 17158246.

23. Ip JE, Cheung JW, Park D, et al. Temporal associations between thoracic volume overload and malignant ventricular arrhythmias: a study of intrathoracic impedance. J Cardiovasc Electrophysiol. 2011; 22(3): 293-299, doi: 10.1111/j.1540-8167.2010.01924.x, indexed in Pubmed: 20946226.

24. Abi-Saleh B, Malozzi C, Charaf E, et al. Worsening thoracic impedance as a ventricular tachyarrhythmia risk. Rev Cardiovasc Med. 2014; 15(3): 226-231, indexed in Pubmed: 25290728.

25. Landolina M, Perego GB, Lunati M, et al. Remote monitoring reduces healthcare use and improves quality of care in heart failure patients with implantable defibrillators: the evolution of management strategies of heart failure patients with implantable defibrillators (EVOLVO) study. Circulation. 2012; 125(24): 2985-2992, doi: 10.1161/CIRCULATIONAHA.111.088971, indexed in Pubmed: 22626743.

26. Gula LJ, Wells GA, Yee R, et al. A novel algorithm to assess risk of heart failure exacerbation using ICD diagnostics: validation from RAFT. Heart Rhythm. 2014; 11(9): 1626-1631, doi: 10.1016/j.hrthm.2014.05.015, indexed in Pubmed: 24846373.

27. Boriani G, Da Costa A, Quesada A, et al. Effects of remote monitoring on clinical outcomes and use of healthcare resources in heart failure patients with biventricular defibrillators: results of the MORE-CARE multicentre randomized controlled trial. Eur J Heart Fail. 2017; 19(3): 416-425, doi: 10.1002/ejhf.626, indexed in Pubmed: 27568392.

28. Böhm M, Drexler H, Oswald H, et al. Fluid status telemedicine alerts for heart failure: a randomized controlled trial. Eur Heart J. 2016; 37(41): 3154-3163, doi: 10.1093/eurheartj/ehw099, indexed in Pubmed: 26984864.

29. Sarkar S, Hettrick DA, Koehler J, et al. Improved algorithm to detect fluid accumulation via intrathoracic impedance monitoring in heart failure patients with implantable devices. J Card Fail. 2011; 17(7): 569-576, doi: 10.1016/j.cardfail.2011.03.002, indexed in Pubmed: 21703529. 